\title{
(Math) Teachers Are the Key
}

\section{Irwin Kra}

Math education is hot. The venerable New York Times published an op-ed piece by S. Garfunkel and D. Mumford in August of 2011 http:// www.nytimes.com/2011/08/25/opinion/ how-to-fix-our-math-education.htm1? $r=2 \& r e f=$ contributors) that, on first reading appears to be right on the mark. However, because it omits several key issues, their proposal invites many negative consequences and would ultimately lead to further delays in solving the problems besetting our troubled educational enterprise. A lively follow-up discussion on the New York Times blog for students (http://1 earning.blogs . nytimes. com/2011/08/26/do-we-need-a-new-way-toteach-math/?scp=1\&sq=Mumford\&st=cse produced about twenty responses by September 19roughly three to one in disagreement with the authors.

Garfunkel and Mumford write, "There is widespread alarm in the United States about the state of our math education. The anxiety can be traced to the poor performance of American students on various international tests ... [T]his worry, however, is based on the assumption that there is a single established body of mathematical skills that everyone needs to know to be prepared for twenty-first-century careers. This assumption is wrong. The truth is that different sets of math

Irwin Kra is Distinguished Service Professor (Mathematics) Emeritus at SUNY, Stony Brook and the founding executive director (retired) of $\mathrm{M} f \mathrm{~A}$, an organization dedicated to improving mathematics learning and teaching in the nation's public schools. His e-mail address is irwinkra@ gmai 1. com.

Members of the Editorial Board for Doceamus are: David Bressoud, Roger Howe, Karen King, William McCallum, and Mark Saul.

DOI: http://dx.doi.org/10.1090/noti816 skills are useful for different careers, and our math education should be changed to reflect this fact."

There is apparently very little to disagree with in the claim. But it completely misses the urgency in addressing the crisis facing us. The "worry" is based mostly on the poor learning and hence poor performance of our high school students who are just not ready at graduation to either succeed in the current job market or in college programs. Garfunkel and Mumford propose major curriculum revisions, in effect to make the curriculum more practical and more relevant to the marketplace. A properly revised curriculum certainly makes sense for many, and perhaps even most, students. Innovative teachers, and not just in high school (see, for example, K. Stroyan's piece in this column-Notices, Volume 58, Number 8), already use many of the ideas (for example, introducing reallife examples) they propose. But here is the rub: there are not enough knowledgeable, talented math teachers in our public, and many private, high schools. Many math classes are taught by people with scant knowledge, and little love, of mathematics. We need to emphasize the need for content knowledge for our teachers. With only superficial understanding of math, one can teach applications of mathematics to neither the real world nor to astrophysics. With the minimal requirements for mathematics knowledge that qualify for most high school teacher certification today, one cannot truly teach mathematics at all. Even more worrisome, the problem begins much earlier, probably in kindergarten, with teachers uneasy with mathematics projecting their uneasiness onto students. No one will ever tell you "English was my worst subject," but many elementary school teachers are unashamed to admit to the claim that "studying math gave me nightmares." 
Any major mathematics curriculum reform, especially the drastic and controversial one proposed by Garfunkel and Mumford, requires a long time to test and implement. Less radical solutions to improve learning are needed now. Improving math teacher quality is a crucial step. Training and selecting better teachers is independent of curriculum revisions. Studies [1] have shown that improved teacher quality can only lead to improved student learning and performance. Unfortunately, the self-evident fact that you need mathematics content knowledge, in addition to pedagogical skills and a personality suited for the classroom, to teach mathematics is not supported, especially on economic grounds, by all studies. Attracting and keeping better teachers in classrooms must involve improving their working conditions, and salaries are a big part of the equation.

Before implementation in the classroom, major curriculum changes require new texts and a thorough reorientation of teacher training programs-a long-term process involving years of testing and experimentation. The complications in designing the right math curricula for this, or any, century are enormous. The resulting timeline for meaningful action is totally unacceptable to serious education reformers, particularly because there are short-term remedies with predictable and positive results.

Another major shortcoming of the Garfunkel and Mumford proposals is that they ignore the concept of student tracking. This emotional and pedagogical issue is guaranteed to generate controversy since the suggested curriculum would certainly not be appropriate for all. With a tracking system, how do you ensure the ability to move from one track to another-we cannot possibly suggest an educational system where the courses taken at the age of twelve completely disqualify students from many choices at age twenty-one. Moreover, it is hard to define what practical mathematics needed by everyone should be. While the plumber might never have to solve a quadratic equation, the town clerk with a building application to review might. And, in view of past and almost certain future nuclear power plant disasters, every voter needs to have some understanding of the concept of decay and half-life.

Where in the curriculum do we address fundamental logical thinking? Traditionally, this has been done in the mathematics curriculum and it probably needs to stay in. Yet, a curriculum narrowly focused on applications would hardly address the core lessons of logic and reasoning. Moreover, in a narrow and applied curriculum, where would we address the intrinsic beauty and poetry in mathematics and other sciences? I believe that these qualities can only be taught by someone with an appreciation for those aspects of the subject. A solid argument can be made for exposing all students to basic and fundamental mathematical concepts, methods, and reasoning. No one knows what the future will demand of our scientists and mechanics. It makes sense to expose everyone to as vast a mathematical landscape as possible.

Educational research and long-term plans for reform are urgently needed, but they cannot be an excuse for delaying some important actions that will certainly do no damage and will very likely improve our enterprise. Improving teacher quality and dramatically raising the bar for content knowledge across the primary and secondary educational establishment is an indispensable good. It has been endorsed by school administrations, by unions, and by parents. ${ }^{1}$ The only thing lacking is the political will to make it happen. If we do not take immediate steps to improve math educationand teacher quality is key here-we will, before long, be a second-rate industrial nation with an undereducated work force. Programs to produce and keep better-trained and better-performing teachers require a nontrivial investment of talent and dollars, money we cannot afford not to spend. The issue is not just money. Too much has been spent on bad and misguided approaches to solving our problems. Not enough attention has been paid to the content knowledge of teachers and in preparing them, and not enough attention is paid to developing the necessary pedagogical skill. The National Science Foundation has produced a video on its website [2] that documents part of the problem and illustrates the work of D. Ball.

To quote Garfunkel and Mumford once more: "Today, American high schools offer a sequence of algebra, geometry, more algebra, pre-calculus, and calculus (or a 'reform' version in which these topics are interwoven). This has been codified by the Common Core State Standards, recently adopted by more than forty states. This highly abstract curriculum is simply not the best way to prepare a vast majority of high school students for life." Again, I agree almost completely, but the codified standards, not perfect instruments by any means, represent a step forward. Build on them. Do not tear them down, and always keep in mind that good teachers are the key. To put good math teachers in the classroom, society must expect more from them, must pay them more, and must give them the support and respect they deserve.

\section{References}

[1] D. H. Monk, Subject area preparation of secondary mathematics and science teachers and student achievement, Economics of Education Review 13 (1994), 125-145.

[2] NSF special report, http://www.nsf.gov/news/ special_reports/math/classroom.jsp.

${ }^{1} \mathrm{R}$. Weingarten, president of the American Federation of Teachers, is a member of the $\mathrm{M} f \mathrm{~A}$ Board, an organization that supports these goals. 